\title{
Comunicación
}

\section{Frecuencia y Clasificación Histopatológica del M astocitoma Cani- no en la Casuística (periodo 2000-2006) de un Laboratorio de Histopatología Veterinaria, Lima, Perú}

\author{
Frequency and Histopathological Classification of Canine Mastocytoma in the \\ Casuistry (Period 2000-2006) of a Histopathology Veterinary Laboratory \\ in Lima, Peru \\ Ronald Heredia N., Rosa Perales C., ${ }^{1,2}$, Alfonso Chavera C. ${ }^{1}$, Luis Tabacchi N. ${ }^{1}$, \\ Gilberto Santillán A. ${ }^{1}$
}

\section{Resumen}

El objetivo del presente estudio fue clasificar el mastocitoma de acuerdo a su grado histológico, a partir de muestras provenientes de necropsias y biopsias caninas diagnosticadas por histopatología en el Laboratorio de Patología Veterinaria de la Facultad de Medicina Veterinaria de la Universidad Nacional Mayor de San Marcos, Lima, Perú, a través de un estudio retrospectivo para el periodo 2000-2006. Se encontraron 40 casos de mastocitomas (4.5\%) en 881 neoplasias caninas. Al clasificar los mastocitomas según su grado histológico se encontró que el $42.5 \%$ fue de grado I (bien diferenciado), el $47.5 \%$ de grado II (moderadamente diferenciado) y el 10\% de grado III (poco diferenciado). Asimismo, el $63.9 \%$ (23/36) de los casos se encontraron en perros Bóxer.

Palabras clave: mastocitoma, grados histológicos, histopatología, neoplasia

\section{Abstract}

The aim of this retrospective study was to classify mastocytomas according to histologic grade from samples of canine necropsies and biopsies diagnosed by histopathology in the Pathology Laboratory of the Faculty of Veterinary Medicine of the National University of San Marcos, Lima, Peru in the period 2000-2006. A total of 40 cases of mastocytomas were found $(4.5 \%)$ in 881 neoplasms. The classification of the

\footnotetext{
${ }^{1}$ Laboratorio de Histología, Embriología y Patología Veterinaria, Facultad de Medicina Veterinaria de la Universidad Nacional Mayor de San Marcos, Lima, Perú

${ }^{2}$ E-mail: rperales_fmv@hotmail.com
} 
mastocytomas based on the histologic grade indicated that el $42.5 \%$ were of grade I (well differentiated), $47.5 \%$ of grade II (moderately differentiated) and $10 \%$ of grade III (poorly differentiated). Moreover, $63.9 \%$ (23/36) cases were found in the Boxer breed.

Key words: mastocytoma, histologic grades, histopathology, neoplasm

\section{INTRODUCCIÓN}

El mastocitoma es una de las neoplasias de piel con mayor incidencia en la especie canina, correspondiendo al 16-21\% de los tumores cutáneos caninos (Vail, 1996; Blackwood et al., 2012). Tiende a afectar a animales maduros con una media de edad de 8.5 años (Macy, 1985; Shelly, 2003; Misdorp, 2004); sin embargo, puede presentarse en cualquier edad, habiendo reportes en canes desde los 4 meses hasta los 18 años de edad (Pulley y Stannard, 1990) y sin predilección de sexo (Blackwood et al., 2012). Los canes de las razas Bóxer, Boston, Terrier, Bull Terrier, Labrador, Retriever, Fox Terrier y Schnauzer son los más predispuestos (Patnaik et al., 1984; Vail, 1996).

El mastocitoma tiene su origen en las células cebadas o mastocitos. Estas células se originan en la médula ósea a partir de células pluripotenciales (CD 34+), se distribuyen a los tejidos por vía sanguínea, donde adquieren gránulos citoplasmáticos y culminan su diferenciación (Paz et al., 2005). Los mastocitos maduros se distribuyen en el tejido conectivo, siendo especialmente abundantes por debajo de las superficies epiteliales (Lemarié et al., 1995). Presentan gránulos citoplasmáticos que contienen sustancias biológicamente activas como histamina, heparina, leucotrienos y diversas citocinas (Couto y Nelson, 2000). Los mastocitos participan en reacciones de hipersensibilidad, procesos inflamatorios agudos y crónicos, estimulación de células $\mathrm{T}$ y defensa contra parásitos (Paz et al., 2005).
El comportamiento biológico de los mastocitomas puede evaluarse a través de la tasa de crecimiento, señales sistémicas, localización del tumor, estadio clínico y grado histológico. De estos, el grado histológico es el más importante pues las células neoplásicas exhiben grados variables de diferenciación (Patnaik et al., 1984; Jones et al., 1997).

El presente estudio tuvo como objetivo la clasificación histopatológica y la gradación de mastocitomas caninos, según el sistema de grados histológicos postulado por Patnaik et al. (1984), a partir de casos registrados en los archivos del Laboratorio de Patología de la Facultad de Medicina Veterinaria (FMV) de la Universidad Nacional Mayor de San Marcos (UNMSM).

\section{Materiales y Métodos}

El presente estudio retrospectivo del mastocitoma canino se llevó a cabo en el Laboratorio de Patología Veterinaria de la FMV-UNMSM, ubicado en el distrito de San Borja, Lima, Perú.

Se revisaron los archivos de patología (protocolos de necropsia, biopsias histopatológicas) comprendido entre el 1 de enero de 2000 y el 31 de diciembre de 2006, y se obtuvieron las fichas de los casos diagnosticados por histopatología como mastocitoma en caninos. Se incluyó la gradación correspondiente en los casos donde no había sido incluida, siguiendo los criterios establecidos por Patnaik et al. (1984), los 
cuales permiten diferenciar a los mastocitomas. Estos son: grado I (bien diferenciado), grado II (moderadamente diferenciado) y grado III (poco diferenciado). Entre los criterios para la gradación se utilizó la cantidad de citoplasma, forma y diferenciación de la célula, forma y color del núcleo, número de nucléolos, número de figuras mitóticas y otras alteraciones celulares o tisulares.

Asimismo, se evaluó la frecuencia de casos de mastocitoma canino según las variables raza (pura y cruzada), edad $(<1,1$ a $<5,5$ a $<9,>9$ años), sexo, localización (cabeza-cuello, tronco y extremidades) y grado histológico.

\section{Resultados}

Se encontraron 881 casos de neoplasias en caninos en el periodo en estudio. De estos, 40 casos ( $4.5 \%$ de las neoplasias) correspondieron a mastocitoma cutáneo canino (Cuadro 1). La distribución de casos de mastocitoma canino según sexo, edad, raza, localización y grado histológico se muestra en el Cuadro 2. La edad media de presentación fue de 5.8 años, presentándose la mayoría de casos (58.8\%) en el grupo de 5 a $<9$ años. El Bóxer fue la raza con más casos (63.9\%), encontrándose también en Dogo Argentino, Sharpei, Basset Hound, Labrador y Siberian Husky, así como en canes de genética mixta. La localización más frecuente fue en las extremidades (54.1\%), y el grado histológico de mayor predominio fue el grado II $(47.5 \%)$.

Los mastocitomas de grado I se caracterizaron por el predominio de células redondas a ovales, similares a los mastocitos normales, dispuestos en cordones o pequeños grupos celulares. De citoplasma abundante y bien delimitado, con núcleos grandes redondos a ovales y ausencia de figuras mitóticas (Fig. 1).

Los mastocitomas de grado II presentaron un aumento de la celularidad e invasión del tejido cutáneo. Las células presentaron una mayor pleomorfismo, perdiéndose el detalle celular, con citoplasma moderado a escaso. Se observan pocas figuras mitóticas y algunas áreas de necrosis y edema (Fig. 2).

Cuadro 1. Frecuencia porcentual de casos de neoplasias y mastocitomas diagnosticados por histopatología por el Laboratorio de Patología de la Facultad de Medicina Veterinaria, Universidad Nacional Mayor de San Marcos, Lima

\begin{tabular}{cccc}
\hline Año & $\begin{array}{c}\text { Neoplasias } \\
(\mathrm{n})\end{array}$ & $\begin{array}{c}\text { Mastocitomas } \\
(\mathrm{n})\end{array}$ & Porcentaje \\
\hline 2000 & 100 & 0 & 0 \\
2001 & 130 & 5 & 3.9 \\
2002 & 112 & 10 & 8.9 \\
2003 & 119 & 5 & 4.2 \\
2004 & 145 & 7 & 4.8 \\
2005 & 121 & 6 & 5.0 \\
2006 & 154 & 7 & 4.6 \\
\hline Total & 881 & 40 & 4.5 \\
\hline
\end{tabular}


Cuadro 2 Distribución de casos de mastocitoma canino diagnosticados por histopatología, según sexo, edad, raza, localización y grado histológico

\begin{tabular}{llcc}
\hline Variables & & $\begin{array}{c}\text { Casos } \\
(\mathrm{n})\end{array}$ & $\begin{array}{c}\text { Frecuencia } \\
(\%)\end{array}$ \\
\hline \multirow{2}{*}{ Sexo } & Macho & 22 & 59.5 \\
& Hembra & 15 & 40.5 \\
Edad & $1 \quad 00$ & 0 \\
& 1 a $<5$ & 10 & 29.4 \\
& 5 a $<9$ & 20 & 58.8 \\
\multirow{2}{*}{ Raza } & $>9$ & 4 & 11.8 \\
& Bóxer & 23 & 63.9 \\
\multirow{4}{*}{ Localización } & Cruzado & 7 & 19.5 \\
& Otras razas puras & 6 & 16.6 \\
\multirow{3}{*}{ Grado histológico } & Cabeza - cuello & 2 & 5.4 \\
& Tronco & 15 & 40.5 \\
& Extremidades & 20 & 54.1 \\
& I & 17 & 42.5 \\
& II & 19 & 47.5 \\
& III & 4 & 10.0 \\
\hline
\end{tabular}

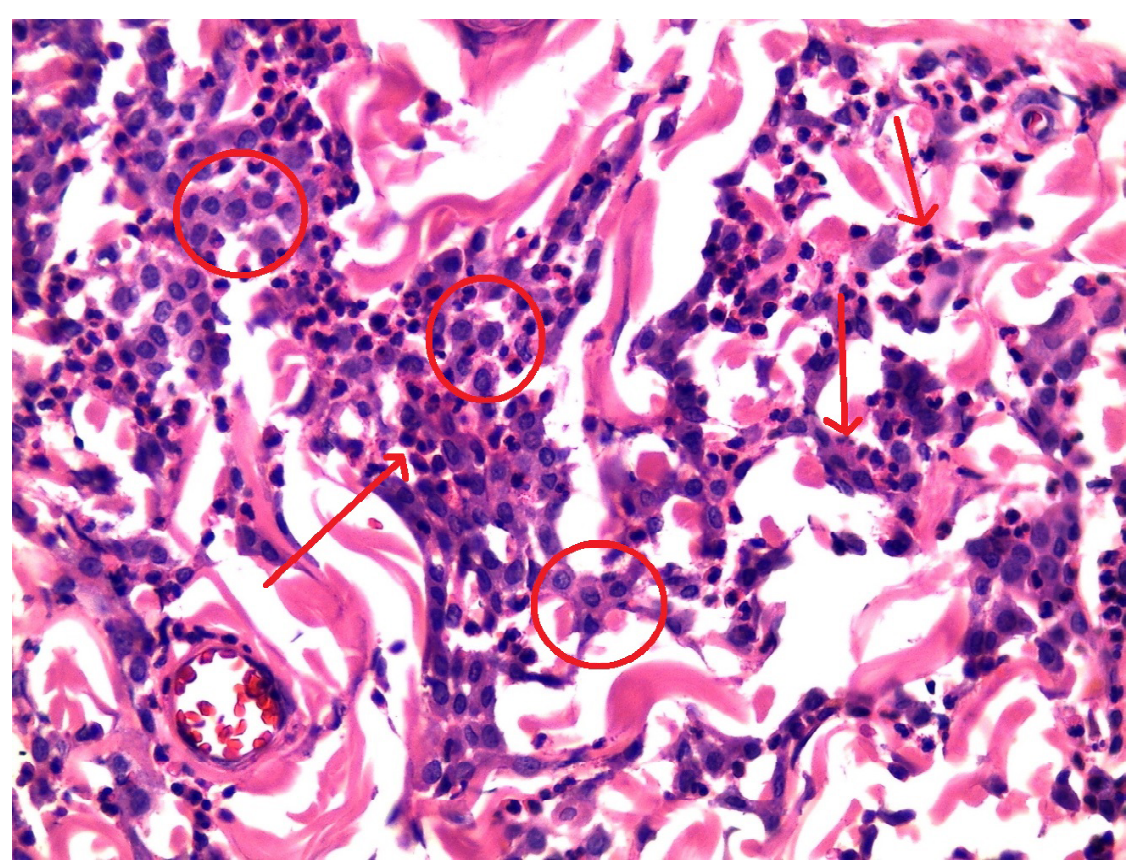

Figura 1. Microfotografía de mastocitoma canino de grado I (H-E, 400X). Se puede observar los mastocitos atípicos con núcleos voluminosos y tenue citoplasma basófilo (en círculo) y la presencia de eosinófilos (flechas) 


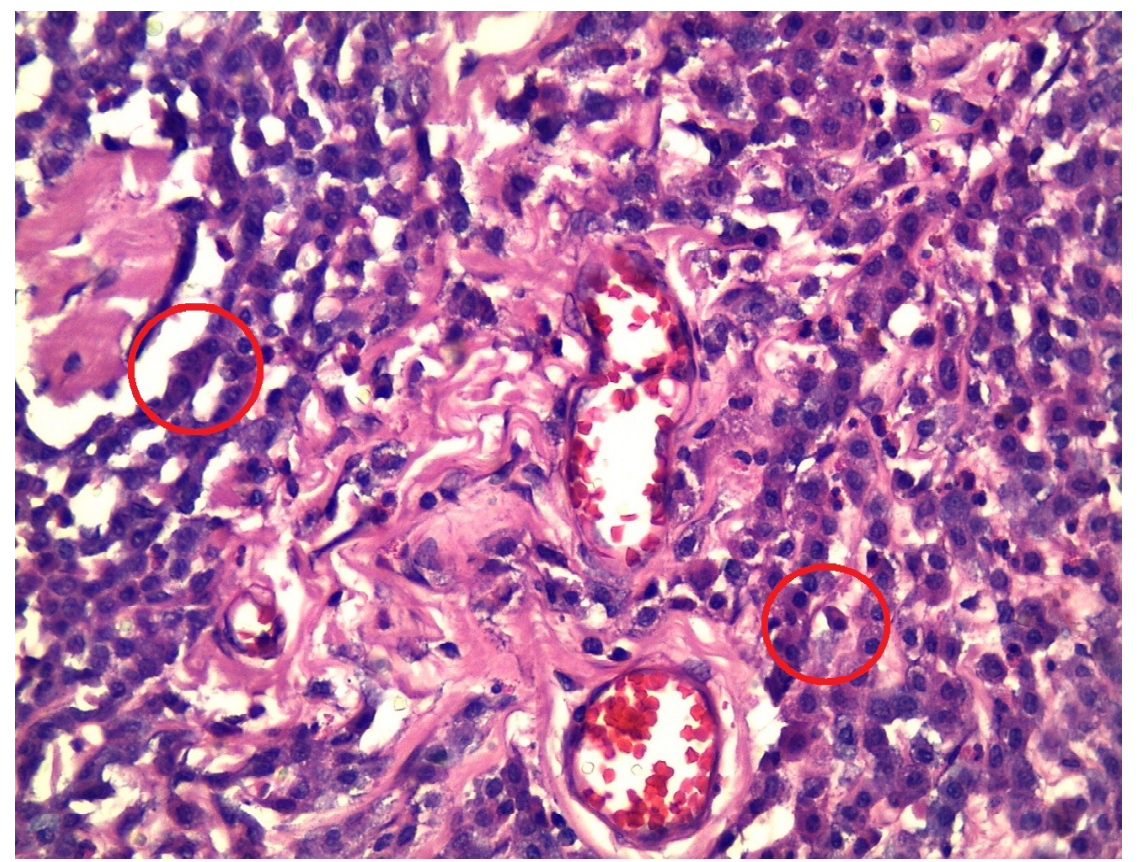

Figura 2. Microfotografía de mastocitoma canino de grado II (H-E, 400X). Se observan mastocitos atípicos voluminosos (en círculo)

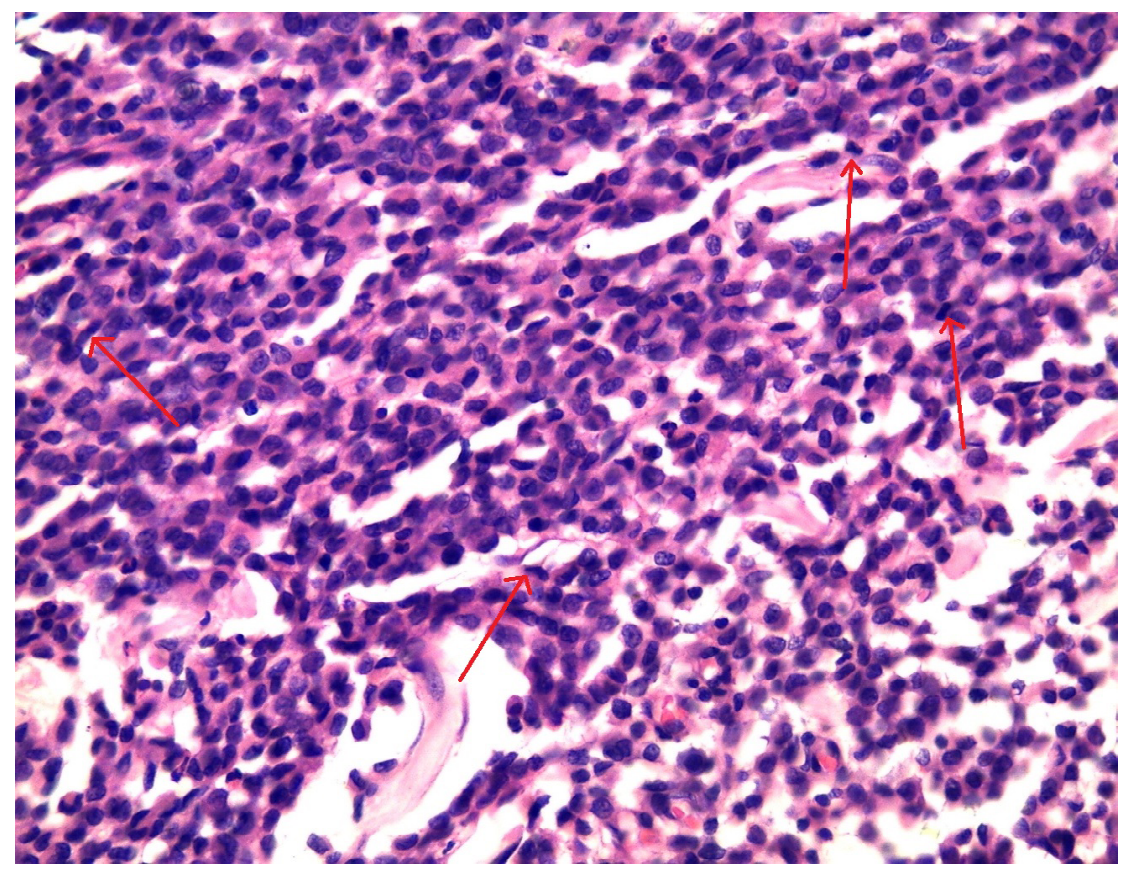

Figura 3. Microfotografía de mastocitoma canino de grado III (H-E, 400X). Se observa abundante proliferación celular atípica y figuras de mitosis (flechas) 
En los mastocitomas de grado III se visualizó una pérdida casi total del detalle celular. La celularidad es abundante y el tejido está completamente invadido. Todas las células presentaron un elevado pleomorfismo. Se observaron algunas células multinucleadas y abundantes figuras mitóticas. Asimismo, extensas áreas de necrosis, hemorragia y edema (Fig. 3).

\section{Discusión}

En el presente estudio se encontró $4.5 \%$ de mastocitomas cutáneos de un total de 881 casos de neoplasias diagnosticadas por histopatología. En otros estudios sobre neoplasias realizados en el país en diferentes periodos, Castro (1985), Díaz (1991), San Martín (2005) y De Vivero (2009) reportaron frecuencias de 8.5, 6.4, 1.3 y $4.5 \%$ de casos, respectivamente.

Sobre la predilección sexual, el mastocitoma se presentó con una tendencia de presentarse con mayor frecuencia en machos que en hembras. Otros autores reportan una mayor proporción de casos en hembras (Simoes y Schoning, 1994; Feltrin, 2007), aunque se indica que no existe predisposición por sexo en la ocurrencia del mastocitoma canino (Lemarié et al., 1995; Scott et al., 1996; Vail, 1996).

La edad promedio de presentación de los mastocitomas fue de 5.8 años, edad inferior a los reportes de 6.8 años de Feltrin (2007) y de 8 años de Vail (1996). La mayor presentación de mastocitomas en animales más jóvenes, en comparación con estos estudios, podría deberse a la creciente contaminación en Lima y a la mejora de las tasas de detección en la práctica de la clínica veterinaria (Cuoto y Nelson, 2000).
La mayor frecuencia de casos en perros Bóxer concuerda con otros estudios (Patnaik et al., 1984; Vail, 1996; Fox, 1998; De Nardi et al., 2000), aunque en dichos estudios se encontraron, además, otras razas con un gran número de casos (Boston Terrier, Bull Terrier, Labrador Retriever, Fox Terrier, Beagle y Schnauzer). Se ha postulado que el Bóxer y el Terrier de Boston poseen oncogenes que se transmiten a la descendencia, lo que, combinado con una deficiencia genética de vigilancia inmunológica, determina una mayor incidencia del mastocitoma en estas razas (Paz et al., 2005).

Respecto a la gradación histológica, los resultados difieren ligeramente de lo encontrado por Patnaik et al. (1984). Determinar el grado histológico es importante, dado que existe un mayor tiempo de supervivencia del animal respecto al grado histológico del tumor (Patnaik et al., 1984). Los animales con mastocitoma de grado I tienen una expectativa de vida dos veces mayor que los de grado II y seis veces mayor que los de grado III (Patnaik et al., 1984).

Las características histológicas halladas en los mastocitomas fueron similares a los indicados en otros trabajos (Patnaik et al., 1984; Rech et al., 2004; Feltrin, 2007).

\section{Conclusiones}

- En la casuística del Laboratorio de Patología de la FMV-UNMSM en el periodo 2000-2006, se encontraron 40 casos de mastocitomas de un total de $881 \mathrm{ca}$ sos de neoplasias caninas, lo que representa el $4.5 \%$.

- $\quad$ El 42.5\% (17/40) de las mastocitomas fueron de grado I, 47.5\% (19/40) de grado II y $10 \%$ (4/40) de grado III. Asimismo, el $63.9 \%$ (23/36) de los casos se encontraron en perros Bóxer. 


\section{Literatura Citada}

1. Blackwood L, Murphy S, Buracco P, De Vos JP, De Fornel-Thibaud P, Hirschberger J, Kessler M, et al. 2012. European consensus document on mast cell tumours in dogs and cats. Vet Comp Oncol 10: e1-e29. doi: 10.1111/ j.1476-5829.2012.00341.x

2. Castro J. 1985. Frecuencia a la presentación de neoplasias en caninos periodo 1978-1983. Tesis de Médico Veterinario. Lima: Univ Nacional Mayor de San Marcos. 42 p.

3. Couto C, Nelson R. 2000. Medicina interna de animales pequeños. $2^{a}$ ed. Buenos Aires: Interamericana. p 1226-1230.

4. De Nardi AB, Rodaski S, Sousa RS, Costa TA. 2002. Prevalencia de neoplasias e modalidades de tratamentos em cäes atendidos no Hospital Veterinario da Universidade Federal do Parana. Arch Vet Sci 7: 15-26. doi: 10.5380/avs.v7i2.3977

5. De Vivero LE. 2009. Frecuencia de neoplasias caninas diagnosticadas en el Laboratorio de Histología, Embriología y Patología Veterinaria de la Facultad de Medicina Veterinaria, Universidad Nacional Mayor de San Marcos. Periodo 1995-2006. Tesis de Médico Veterinario. Lima: Univ Nacional Mayor de San Marcos. 63 p.

6. Díaz M. 1991. Procesos neoplásicos en caninos, análisis estadístico. Tesis de Médico Veterinario. Lima: Univ Nacional Mayor de San Marcos. 26 p.

7. Feltrin M. 2007. Estudo da aplicabilidade de criterios morfológicos e morfométricos para a graduaçäo de mastocitomas cutáneos em caninos. Tesis de Magíster. Pelotas: Univ Fed de Pelotas. 59 p.

8. Fox LE. 1998. Mast cell tumors. En: Morrison WB (ed). Cancer in dogs and cats: medical and surgical management. Baltimore: Williams \& Wilkins. p 477-486.

9. Jones TC, Hunt RD, King NW. 1997. Patología veterinaria. $6^{\mathrm{a}}$ ed. Sao Paulo: Manole. 1415 p.
10. Lemarié JR, Lemarié LS, Hedlund SC. 1995. Mast cell tumors: clinical management. Comp Cont Educ Pract 17: 1085-1101.

11. Macy DW. 1985. Canine mast cell tumors. Vet Clin N Am-Small 15: 783803.

12. Misdorp W. 2004. Mast cells and canine mast cell tumors: a review. Vet Q 26: 156-169.

13. Patnaik AK, Ehler WJ, MacEwen EG. 1984. Canine cutaneous mast cell tumor: morphologic grading and survival time in 83 dogs. Vet Pathol 21: 469-474.

14. Paz N, Fogel F, Denzoi L. 2005. Mastocitoma cutáneo: dos casos en una familia de perros Bóxer. Universidad del Centro Tandil, Argentina. Veterinarios en web [Internet]. Disponible en: http:// veterinariosenweb.com/revista/capitulo8/nota2-1.html

15. Pulley LT, Stannard AA. 1990. Tumors of the skin and soft tissues. En: Moulton JE (ed). Tumors in domestic animals. $3^{\mathrm{a}}$ ed. California: University of California. p 23-87.

16. Rech RR, Graça DL, Kommers GD, Sallis ESV, Raffi MB, Garmatz SL. 2004. Mastocitoma cutáneo canino. Estudo de 45 casos. Arq Bras Med Vet Zootec 56: 441-448.

17. San Martín AM. 2005. Neoplasias caninas: evaluación estadística. Periodo 1990-1994. Tesis de Médico Veterinario. Lima: Univ Nacional Mayor de San Marcos. $46 \mathrm{p}$.

18. Scott DW, Miller WH, Griffin CE. 1996. Tumores neoplásicos y no neoplásicos. Dermatología de pequeños animales. $6^{\mathrm{a}}$ ed. Intermédica. $1572 \mathrm{p}$.

19. Shelly SM. 2003. Cutaneous lesions. Vet Clin N Am-Small 33: 1-46.

20. Simoes JPC, Schoning P. 1994. Canine mast cell tumors: a comparison of staining techniques. J Vet Diag Invest 6: 458-465.

21. Vail D.M. 1996. Mast cell tumors. In: Withrow SJ, Macewen EG (eds). Small animal clinical oncology. $2^{\mathrm{a}}$ ed. Philadelphia: WB Saunders. p 192-210. 